\title{
In vitro binding of several cell-specific and ubiquitous nuclear proteins to the GT-I motif of the SV40 enhancer
}

\author{
Jia-Hao Xiao, Irwin Davidson, Mary Macchi, Ricardo Rosales, Marc Vigneron, Adrien Staub, and \\ Pierre Chambon \\ Laboratoire de Génétique Moléculaire des Eucaryotes du CNRS, Unité 184 de Biologie Moléculaire et de Génie Génétique de \\ l'INSERM, Faculté de Médecine, 67085 Strasbourg Cédex, France
}

\begin{abstract}
We have investigated the specific in vitro binding of nuclear proteins from several cell lines to the GT-I motif of the SV40 enhancer which overlaps with the canonical enhancer "core" homology. The binding of three proteins (GT-IA, GT-IB, and GT-IC), one of which (GT-IC) exhibits cell specificity, was detected. Competition and direct binding experiments demonstrated that the two ubiquitous proteins also bind to the GC-rich motif III from the 21-bp repeat upstream element of the SV40 early promoter and that protein GT-IA is most probably the transcription factor Sp1. The third, cell-specific protein GT-IC exhibited a high affinity for both the GT-I motif and an upstream element in the promoter of the mouse $\beta$-major-globin gene, suggesting that this protein can act both as an enhancer and an upstream element trans-acting factor. The good correlation between the known cell-specific in vivo activity of the wild-type and mutated GT-I motif and the cell-specific binding of protein GT-IC in vitro strongly supports the conclusion that this protein is an enhancer factor. Interestingly, its cognate recognition sequence does not coincide with the core homology.
\end{abstract}

[Key Words: Transcription factor; SV40 enhancer; $\beta$-globin promoter upsteam element; DNA-binding protein; lymphoid cells; F9 embryonal carcinoma cells; Spl factor]

Received May 4, 1987; revised version accepted July , 1987.

The enhancer of simian virus 40 (SV40) is a member of a class of cis-acting regulatory elements that stimulate transcription in vivo from eukaryotic RNA polymerase class B (II) promoters (Banerii et al. 1981; Moreau et al. 1981; for reviews, see Chambon et al. 1984; Picard 1985; Serfling 1985; Sassone-Corsi and Borrelli 1986; Wasylyk 1986). This activity, which is independent of the orientation and to some extent of the location of the element, is mediated by trans-acting factors (Borrelli et al. 1984; Schöler and Gruss 1984; Ephrussi et al. 1985; Mercola et al. 1985; Schöler et al. 1986; Wasylyk et al. 1987). Enhancer elements have been found associated with a number of cellular and viral genes /see reviews above and references therein) and may exhibit ubiquitous or cell-specific activity (Banerii et al. 1983; Gillies et al. 1983; Queen and Baltimore 1983; Walker et al. 1983; Schirm et al. 1987; see also reviews above).

In vivo studies have shown that the SV40 enhancer consists of multiple sequence motifs that act synergistically to generate enhancer activity in HeLa cells (Herr and Clarke 1986; Zenke et al. 1986). These sequence motifs, GT-II, GT-I, TC-II, Sph-I, Sph-II, and P, are organized in two domains, $A$ and $B$ (Fig. 1), whose multimerization generates enhancer activity (Zenke et al. 1986). While no extensive sequence homology exists between different enhancers, comparison of the DNA sequences of a number of enhancers led to the definition of an en- hancer "core" sequence (5'-GTGG A/T A/T A/T G-3"; Laimins et al. 1982; Weiher et al. 1983). The GT-I and GT-II motifs of the SV40 enhancer show high homology to this consensus motif.

The activity of several enhancers, including that of SV40, has been partially reproduced in vitro (SassoneCorsi et al. 1984, 1985; Sergeant et al. 1984; Wildeman et al. 1984; Schöler and Gruss 1985; Augereau and Chambon 1986; Dougherty et al. 1986). In vitro DNase I footprinting studies have shown that each of the sequence motifs of the SV40 enhancer binds a protein(s) present in HeLa cell nuclear extracts (Davidson et al. 1986; Wildeman et al. 1986). The binding of these proteins is prevented by the mutations that are detrimental to enhancer activity in vivo, suggesting that these proteins are the trans-acting factors that mediate enhancer activity in vivo. This idea is further supported by the observation that the overlapping Sph and octamer motifs (see Fig. 1) and the GT-II motif region exhibit a cell-specific activity (Davidson et al. 1986; Nomiyama et al. 1987) and that the proteins that bind in vitro to these motifs show the same cell specificity (Davidson et al. 1986; Rosales et al. 1987; Xiao et al. 1987). The results of footprinting experiments indicate that the GT-I motif is not identically protected from DNase I digestion by the proteins present in HeLa and lymphoblastoid BJA-B cell extracts (Davidson et al. 1986), suggesting that this 


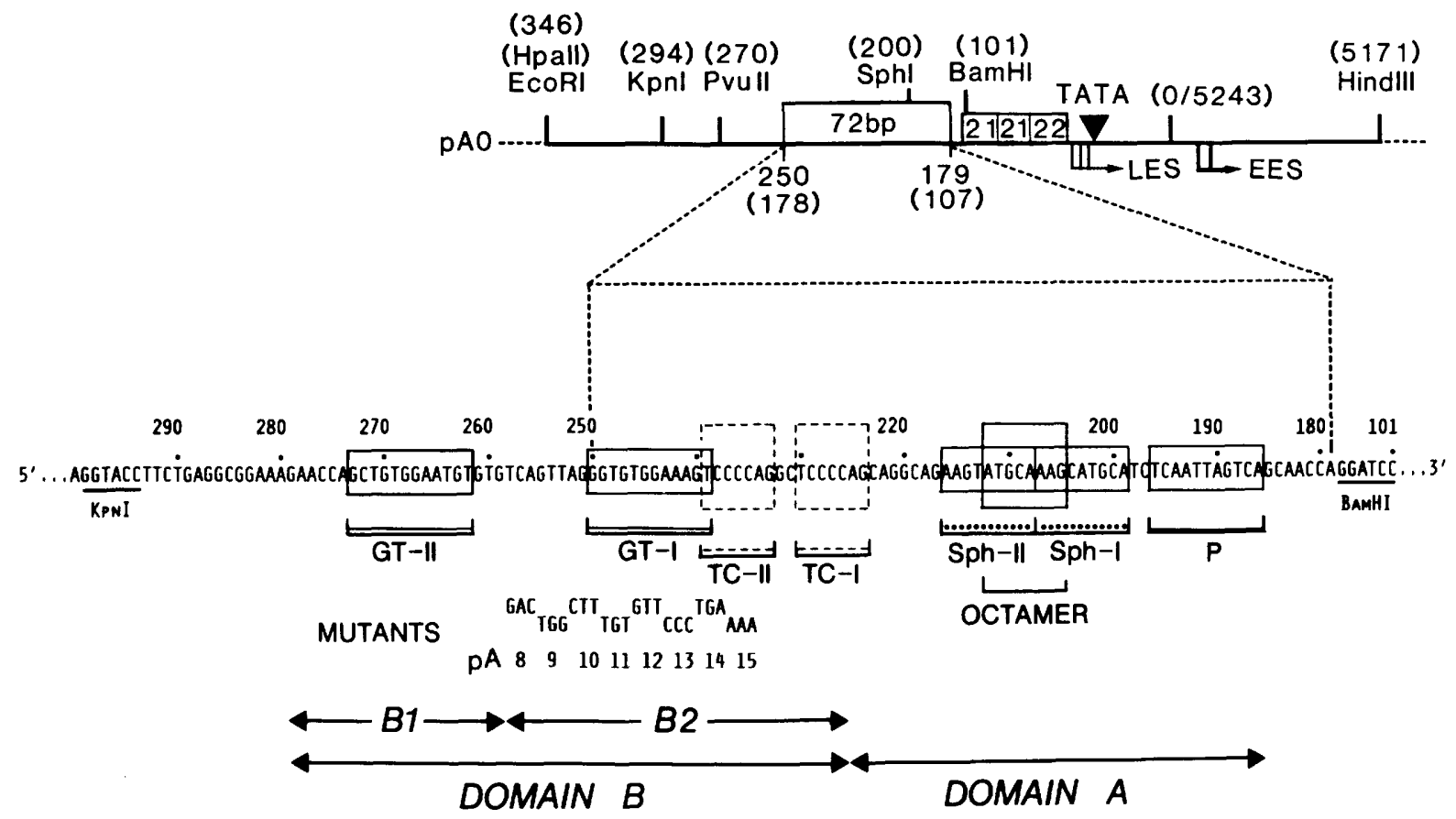

Figure 1. Organization of the SV40 early promoter. The top line shows the structure of the SV40 early promoter in plasmid pA0 (Zenke et al. 1986), containing only one copy of the 72-bp sequence. The positions of the essential elements of the promoter, the TATA box, the 21-bp repeat element $(21,21,22)$, and the 72 -bp enhancer element, are indicated along with the coordinates (BBB system, Tooze 1982) of several natural or engineered restriction enzyme recognition sites. EES and LES indicate the positions of the early-early and late-early mRNA start sites, respectively. The second line shows the sequence of the late coding strand of the 72 -bp element (indicated by the vertical broken lines) and the $5^{\prime}$-flanking sequences. The locations of the sequence motifs that have been identified in the enhancer are indicated by the boxes, along with the positions of the A, B1, and B2 enhancer domains. pA mutants refer to the late coding strand sequences present in mutated recombinants pA8-pAl5 (Zenke et al. 1986; Nomiyama et al. 1987).

motif may also be recognized by cell-specific proteins. In this report we investigate the in vitro binding of nuclear proteins from several cell types to the GT-I motif.

\section{Results}

Several nuclear proteins interact with the enhancer motif GT-I in vitro

To study the interaction of nuclear factors with the enhancer motif GT-I in isolation from the other enhancer motifs, two templates containing the motif in either a wild-type or mutated form were constructed [pGT1-0 and pGT1-1 (see Fig. 2 and Materials and methods)]. pGT1-0 contains the wild-type GT-I motif (nucleotides 238-255; BBB numbering system, Tooze 1982), while pGT1-1 contains a cluster of three point mutations identical to those present in recombinant pA12 (see Figs. 1 and 2 and Zenke et al. 1986). This mutation was shown to be deleterious to enhancer activity in vivo in HeLa cells and to prevent the binding of a nuclear protein(s) to the GT-I motif in the SV40 enhancer in vitro (Wildeman et al. 1986).

The ${ }^{32} \mathrm{P}-5^{\prime}$-end-labeled templates pGT1-0 and pGT1-1 were incubated with nuclear extracts from various cell lines in the presence of poly (dA-dT) as a competitor for "nonspecific" DNA-protein interactions. The resulting complexes were separated by electrophoresis on a nondenaturing polyacrylamide gel (Fried and Crothers 1981;
Garner and Revzin 1981; Strauss and Varshavsky 1984). Incubation of pGT1-0 with a HeLa cell nuclear extract resulted in the formation of three complexes $\mathrm{A}, \mathrm{B}$, and $\mathrm{C}$ (Fig. 3A). Complexes with analogous electrophoretic mobilities to $A$ and $B$ were formed using nuclear extracts from the human Burkitt lymphoma-derived cell line BJA-B (Klein et al. 1975), the human T-cell line Molt-4 (Minowada et al. 1972), the mouse pre-B cell line 70Z/3 before (NI) and after (I) (data not shown) induction with lipopolysaccharide (LPS) (Paige et al. 1978; Sakaguchi et al. 1980), the mouse myeloma cell line MPC11, undifferentiated mouse F9 embryonal carcinoma cells [F9(ND)], and simian CV1 kidney cells (see the respective lanes in Fig. $3 \mathrm{~A}$ ). In contrast, a complex with analogous mobility to complex $\mathrm{C}$ of HeLa cell extracts was formed only in CV1 cell extracts; MPC11 cell extracts failed to form any third complex and F9(ND) cell extracts formed a slower migrating complex C. Complexes $C$ with slightly different mobilities were also seen with BJA-B (in which two bands can be distinguished), Molt-4, and 70Z/3 noninduced and induced (data not shown) cell extracts (compare complex $C$ in each cell type in Fig. 3A). Formation of these complexes was dramatically reduced using the mutated template pGT1-1 (Fig. 2), indicating that the interaction was specifically mediated by the GT-I motif (Fig. 3A). Note, however, that the formation of complex A appears to be less affected by the mutation than that of complexes $B$ and $C$ 


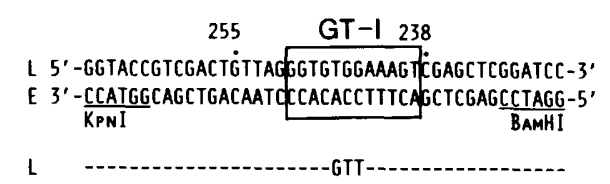

244
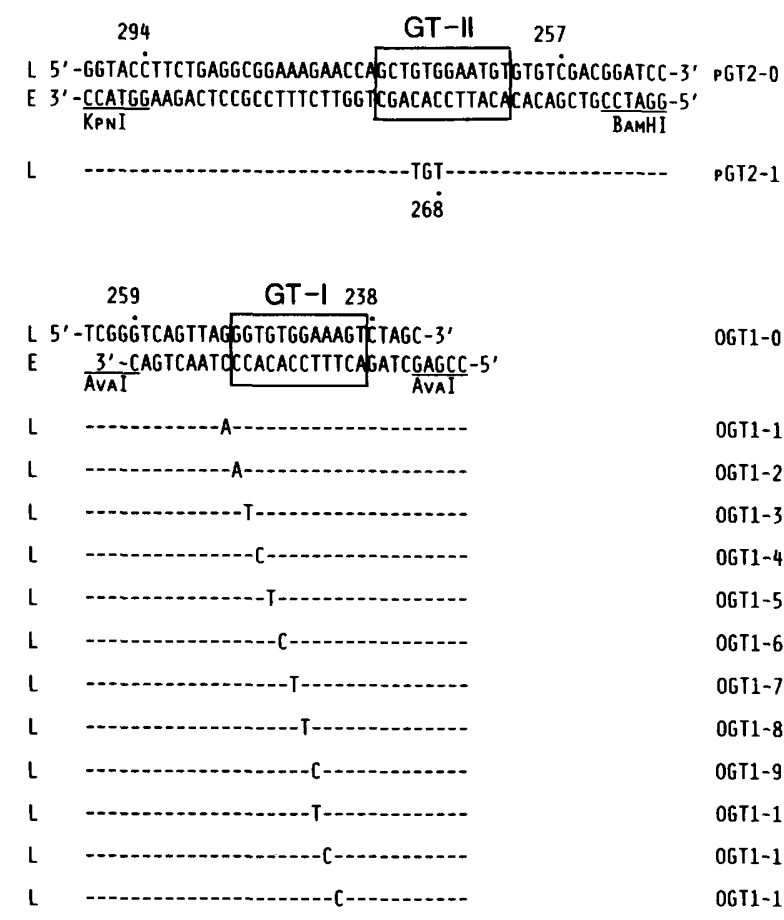

OGT1-0
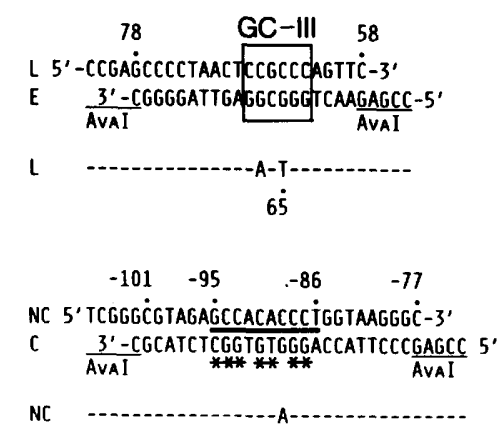

OBG -0

OBG-1

Figure 2. Sequences of enhancer motif-containing templates. The top line indicates the sequence of the pGT1-0 template which contains the wild-type GT-I motif. The location of the mutations present in the template pGT1-1 is indicated immediately below. pGT2-0 and pGT2-1 contain the wild-type and mutated GT-II motif from the SV40 enhancer, respectively. Template OGT1-0 contains the wild-type GT-I motif, while OGT1-1 to OGT1-12 contain single point mutations, the locations of which are indicated below the wild-type sequence. Templates OGC3-0 and OGC3-1 contain the wild-type and mutated GC-III motif from the SV40 21-bp repeat region (Barrera-Saldana et al. 1985), respectively. Templates OBG-0 and OBG-1 contain the wild-type or mutated mouse $\beta$-major-globin promoter upstream region from positions -77 to -101 (Dierks et al. 1983; Myers et al. 1986). The region of homology to the GT-I motif is indicated by the bar between the globin mRNA coding $(\mathrm{C})$ and noncoding (NC) strands. The stars indicate the positions of the single point mutations that are detrimental to this promoter activity in HeLa cells (Myers et al. 1986). E and L refer to the SV40 early and late mRNA coding strands, respectively. [see F9 (ND) in Fig. 3A]. Similar results were obtained using poly (dI-dC) rather than poly (dA-dT) as a nonspecific competitor, with the exception of the complexes $\mathrm{C}$ that were markedly weaker using poly(dI-dC) (compare Fig. 3, A and B). Several minor specific or nonspecific (i.e., present using the mutant pGT1-1) complexes migrating faster were also generated. These minor specific complexes may be due to partial proteolysis of the major complexes, as their intensity was reduced in extracts prepared in the presence of higher concentrations of protease inhibitors (data not shown).

The sequence specificity of the HeLa and BJA-B complexes $A, B$, and $C$ was further studied in competition experiments. The HeLa and BJA-B complexes were competed by an excess of wild-type pGT1-0, but not mutant pGT1-1 (Fig. 3B). [Note that in these competition experiments and in those presented below the labeled DNA template was not present in excess as shown by titration with increasing amounts of DNA template (data not shown).] Complex $\mathrm{C}$ was in each case competed more efficiently than complexes A and B. Densitometric scannings of autoradiograms corresponding to experiments similar to those presented in Figure $3 \mathrm{~B}$ indicate that complexes $\mathrm{B}$ and $\mathrm{C}$ were competed two times and five to 10 times more efficiently than complex A, respectively (see also Fig. 7A, below). Moreover both bands forming the BJA-B complex $C$ were similarly competed. In marked contrast, no competition was observed with the closely related GT-II motif /see pGT2-0 and pGT2-1 in Figs. 2 and $3 \mathrm{~B}$ ), indicating that these two sequences interact with different nuclear proteins. Under similar conditions, no competition was observed using the other motifs from the SV40 enhancer (P, Sph-I and Sph-II, octamer, and TC-II), the adenovirus 2 (Ad2) binding sites for nuclear factors NF-I (Rosenfeld and Kelly 1986; Rosenfeld et al. 1987) and NF-III (Pruijn et al. 1986), the herpes simplex virus type 1 thymidine kinase (McKnight et al. 1984; Jones et al. 1987) and MHC E $a$ CAAT box motifs, the Ephrussi $\mu \mathrm{E} 1$ and $\mu \mathrm{E} 3$ motifs from the $\operatorname{IgH}$ enhancer (Ephrussi et al. 1985; Peterson et al. 1986; Sen and Baltimore 1986; Weinberg et al. 1986), the core homology from the Ad2 E1A enhancer (Hen et al. 1983; Barrett et al. 1987), and part of the B domain of the wildtype or mutant PyEC9.1 polyoma virus enhancer (for references, see Herbomel et al. 1984; Xiao et al. 1987) (data not shown, the sequences of the competitor templates are described in the legend to Fig. 3B).

Complexes $A, B$, and $C$ are formed by interaction with three nonidentical proteins, one of which exhibits cell specificity

The results in Figure 3, A and B, suggest that three different nuclear proteins, one of which possibly exhibits cell specificity, may interact with the GT-I motif. To test this hypothesis, the HeLa or BJA-B cell extracts were applied to a heparin-agarose column and the retained proteins eluted with a linear $0.2-0.6 \mathrm{M} \mathrm{KCl}$ gradient (Materials and methods). The eluted fractions were analyzed using the pGT1-0 template. The peaks of the proteins forming complexes $\mathrm{A}$ and $\mathrm{B}$ were eluted at different $\mathrm{KCl}$ concentrations for both the HeLa and BJA-B 


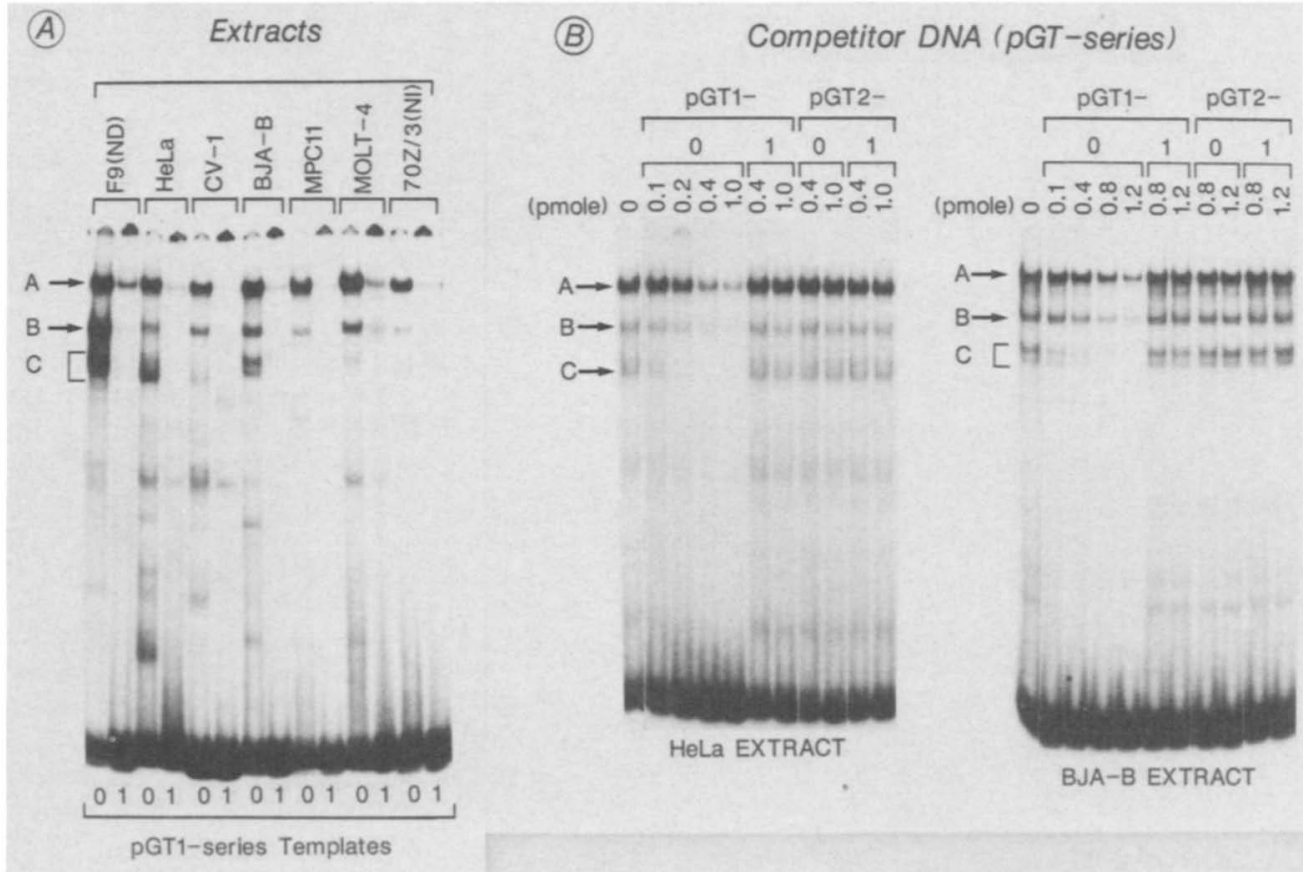

Figure 3. (A) In vitro protein binding to the wild-type (pGT1-0) and mutated (pGT1-1) GT-I motif. The origins of the nuclear extracts and the DNA templates used are indicated above and below the lanes, respectively. The positions of the A, B, and C complexes are indicated to the left of the figure. Each binding reaction contained a constant amount $(2 \mu \mathrm{g})$ of poly $(\mathrm{dA}-\mathrm{dT})$ and either $8 \mu \mathrm{g}$ of $\mathrm{F} 9$ extract, $16 \mu \mathrm{g}$ of HeLa extract, $12 \mu \mathrm{g}$ of CV1 extract, $12 \mu \mathrm{g}$ of B/A-B extract, $16 \mu \mathrm{g}$ of MPC11 extract, $16 \mu \mathrm{g}$ of Molt-4 extract, or $16 \mu \mathrm{g}$ of $7 \mathrm{OZ} / 3(\mathrm{NI})$ extract. $(B)$ Competition gel retardation experiments using the wild-type and mutated GT-I and GT-II motifs. The origin and quantity (in pmoles) of competitor DNA used are indicated above each lane. In each case, the template was the wild-type GT-I motif in pGT1-0. The positions of A, B, and C complexes formed with $16 \mu \mathrm{g}$ of either the HeLa or the BJA-B nuclear extract are indicated. No competition was observed with oligonucleotides containing: the other SV40 enhancer motifs, TC-II [5'-(245)GGAAAGTCCCCAGG(232)-3'], P [5'-(201)GCATCTCAATTAGTCAGCAACCA(179)-3'] and Sph [5'-(222)AGGCAGAAGTATGCAAAGCATGCATCT(196)-3']; the murine IgH enhancer motif $\mu$ E1 [5'-(343)TTGAGTCAAGATGGCCGATCAG(364)-3'] and $\mu E 3\left[5^{\prime}-(394)\right.$ AGCAGGTCATGTGGCAAGGCTA(415)-3']; the CAAT box (in the opposite orientation) of the MHC E $\alpha$ gene [5'-(-74)GTCTGAAACATTTTTCTGATTGGTTAAAAGTTGAGTGCT(-36)-3']; the "core" sequence of the Ad2 E1A enhancer

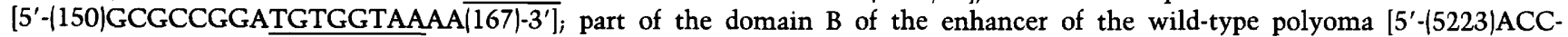
CAGGCCTAGAATGTTTCCACC(5246)-3'] and of the mutant isolate PyEC9.1 [5'-(5223)ACCCAGGCCTGGAATGTTTC$\left.\mathrm{CACC}(5246)-3^{\prime}\right]$; the Ad2 binding site for nuclear factor I (NF-I) [5' $-(15)$ TACCTTATTTTGGATTGAAGCCAATATGATAA(46)-3']; the Ad2 binding site for nuclear factor III (NF-III) [ $5^{\prime}-(29)$ TTGAAGCCAATATGATAATGAGGGGGTGGAG(59)-3']; or the HSV thymidine kinase (TK) promoter CAAT box [ $5^{\prime}-(-95)$ CGTCTTGTCATTGGCGAATTCGAACACG $\left.(-68)-3^{\prime}\right]$. In each case only the motif (underlined) and the immediately flanking sequences are shown.

extracts $(0.32-0.38$ and $0.36-0.42 \mathrm{M} \mathrm{KCl}$ for complexes $A$ and $B$, respectively; Fig. $4 A, B)$. The HeLa protein forming complex $C$ was almost coeluted with complex $B$, while the BJA-B proteins forming complex $\mathrm{C}$ were present in the $0.1 \mathrm{M} \mathrm{KCl}$ wash (Fig. $4 \mathrm{~A}, \mathrm{~B}$ and data not shown; note that the two complexes eluted in the BJA-B gradient which appear to comigrate with complex $C$ were also present with the GT-I motif mutant pGTl-1 and therefore do not correspond to complex $\mathrm{C}$, data not shown). Thus, while the $\mathrm{A}$ and $\mathrm{B}$ complexes are formed by apparently analogous proteins in each cell type, no protein equivalent to the HeLa complex $\mathrm{C}$ was found in BJA-B cell extracts, and vice versa. In agreement with the results obtained with the crude nuclear extracts, no complex C similar to either HeLa or BJA-B complexes C was found in MPC11 cell extracts after heparin-agarose chromatography (data not shown). These results support the idea that complexes A, B, and C are formed by interaction with three nuclear proteins that differ in apparent molecular weight and charge. Similar chromatographic separations could not be performed with F9 extracts due to limiting amounts of material.

The proteins forming complexes $A, B$, and $C$ interact with closely overlapping sequences

Formation of complexes $\mathrm{A}, \mathrm{B}$, and $\mathrm{C}$ was greatly reduced by the mutations present in pGT1-1 (see Fig. 3A), suggesting that the three proteins interact with the same or closely overlapping sequences. To distinguish these two possibilities, we performed methylation interference experiments (Hendrickson and Schleif 1985 and references therein) to determine which guanine $(G)$ residues were important in the formation of each complex. The pGT1-0 template DNA was partially methylated in vitro with dimethylsulfate (DMS). Following electrophoresis, the complexes formed with these modified templates were eluted from the gel and the DNA cleaved at the 


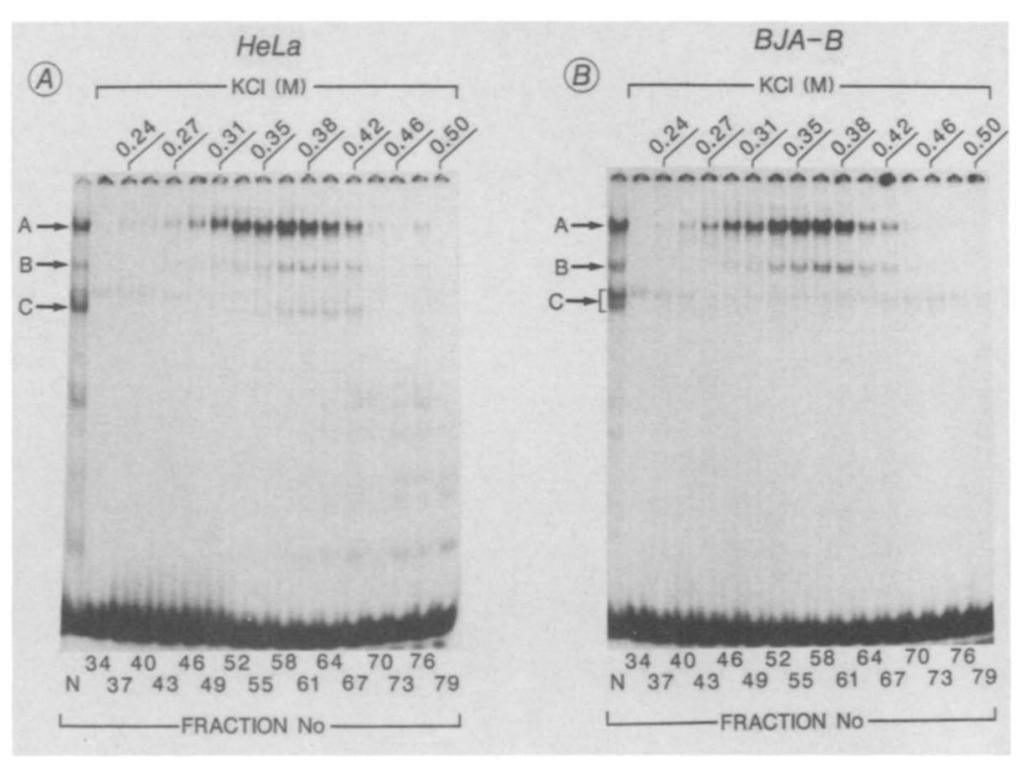

Figure 4. Chromatographic fractionation of the HeLa and BJA-B cell nuclear extracts. $|A|$ The elution pattern of the HeLa cell proteins forming the $\mathrm{A}$, $\mathrm{B}$, and $\mathrm{C}$ complexes from the heparin-agarose column was followed using the wild-type GT-I motif template pGT1-0. The ionic strength of every sixth fraction is indicated at the top of the figure and the fraction number at the bottom. The positions of the $\mathrm{A}, \mathrm{B}$, and $\mathrm{C}$ complexes formed using the total HeLa cell nuclear extract $(\mathrm{N})$ are indicated on the left-hand side. Each subsequent lane contains 6 $\mu \mathrm{l}$ of the appropriate fraction and $2 \mu \mathrm{g}$ poly $(\mathrm{dA}-\mathrm{dT})$. $(B)$ The elution pattern of the BJA-B cell proteins forming complexes $\mathrm{A}, \mathrm{B}$, and $\mathrm{C}$ was monitored with the wild-type GT-I motif in template pGT1-0. The nomenclature is as in $A$. Note that the two complexes that appear to comigrate with the complex $C$ present in nuclear extracts were also formed with the mutated pGT1-1 template (data not shown) and thus do not correspond to complex $C$. Results similar to those presented in $A$ and $B$ were obtained reproducibly using independently prepared nuclear extracts. position of the modified $G$ residues by treatment with piperidine (Maxam and Gilbert 1980). G residues that are underrepresented in the DNA from the complex relative to the free and the starting DNA (B, F, and S, respectively, in Fig. 5A) are those whose methylation interfered with complex formation. Formation of HeLa complexes A and C was prevented by methylation of G244, G245, G247, and G249-G251, while the formation of complex B was comparatively less affected by methylation at G247 and G251 (Fig. 5A). Similar results were obtained using BJA-B and undifferentiated F9 cell extracts for each of the complexes formed with these extracts (data not shown; note however that since the two bands forming the BJA-B complex C migrate too closely to be eluted separately, the results represent a composite of two possibly different patterns). Thus, in this assay the proteins forming complexes $\mathrm{A}$ and $\mathrm{C}$ appear to bind similarly to the GT-I motif, while the protein forming complex B may interact differently.

The sequence requirements for the formation of complexes A, B, and C were investigated further in gel retardation experiments with a series of ${ }^{32} \mathrm{P}-5^{\prime}$-end-labeled templates containing point mutations throughout the GT-I motif (OGT1-0 to OGT1-12 in Fig. 2). The resulting A, B, and C complexes were quantitated by densitometric scanning of several exposures of the autoradiograms and the results are presented schematically in Figure 6. Formation of complexes A, B, and C in HeLa cell extracts (Fig. 5B and Fig. 6A) was completely inhibited by single point mutations at positions 245 and 247-250 (OGT1-7, OGT1-2 to OGT1-5), while mutations at positions $251,246,244$, and 241 only partially prevented binding (OGT1-1, OGT1-6, OGT1-8, and OGT1-12), and mutations at positions 243 and 242 had little effect (OGT 1-9 to OGT 1-11). These observations indicate that while all of the mutations, with the possible exception of that at position 244 , similarly affected the formation of complexes $\mathrm{A}$ and $\mathrm{B}$ (compare A and $\mathrm{B}$ ratios in Fig. 6A), several mutations at positions 251, 244 , and 241 affected more markedly the formation of complex A than that of complex C.

Comparison of the results obtained with HeLa cell extracts with those obtained using F9(ND) cell extracts shows that, while complex A behaved in a similar manner in each extract, complexes $B$ and $C$ exhibited a different response (compare complexes $A$ in Fig. 5B,C and Fig. 6). Formation of complex $B$ was increased in F9(ND) cell extracts by the mutations at positions 241-244, while it was either unaffected (positions 242-243) or decreased (positions 241 and 244) by the same mutations using HeLa cell extracts. Similarly, formation of complex $\mathrm{C}$ was more dramatically affected in F9(ND) than in HeLa cell extracts by mutation at position 251. Mutations at positions 241-243 all significantly (2.5-3 times) increased formation of complex C in F9(ND) extracts, while the same mutations had only a minimal effect in HeLa extracts (compare complexes $\mathrm{C}$ in Fig. 5B,C and in the histograms in Fig. 6). These observations show that the behavior of complexes B and C with the mutated templates is different in each extract, while the formation of complex A is similarly affected by the mutations in the two cell extracts. Thus, although complex A may be formed by the same protein in each extract, the complexes $B$ and $C$ may correspond to different proteins. All of the $\mathrm{A}, \mathrm{B}$, and $\mathrm{C}$ complexes formed on the mutated templates could be competed in both extracts by the wild-type OGT1-0 template, demonstrating that no new complex was formed (data not shown).

The proteins forming complexes $A$ and $B$ interact in vitro with the GC-rich motif

We found in competition experiments (not shown) that the SV40 21-bp repeat region which contains the six 


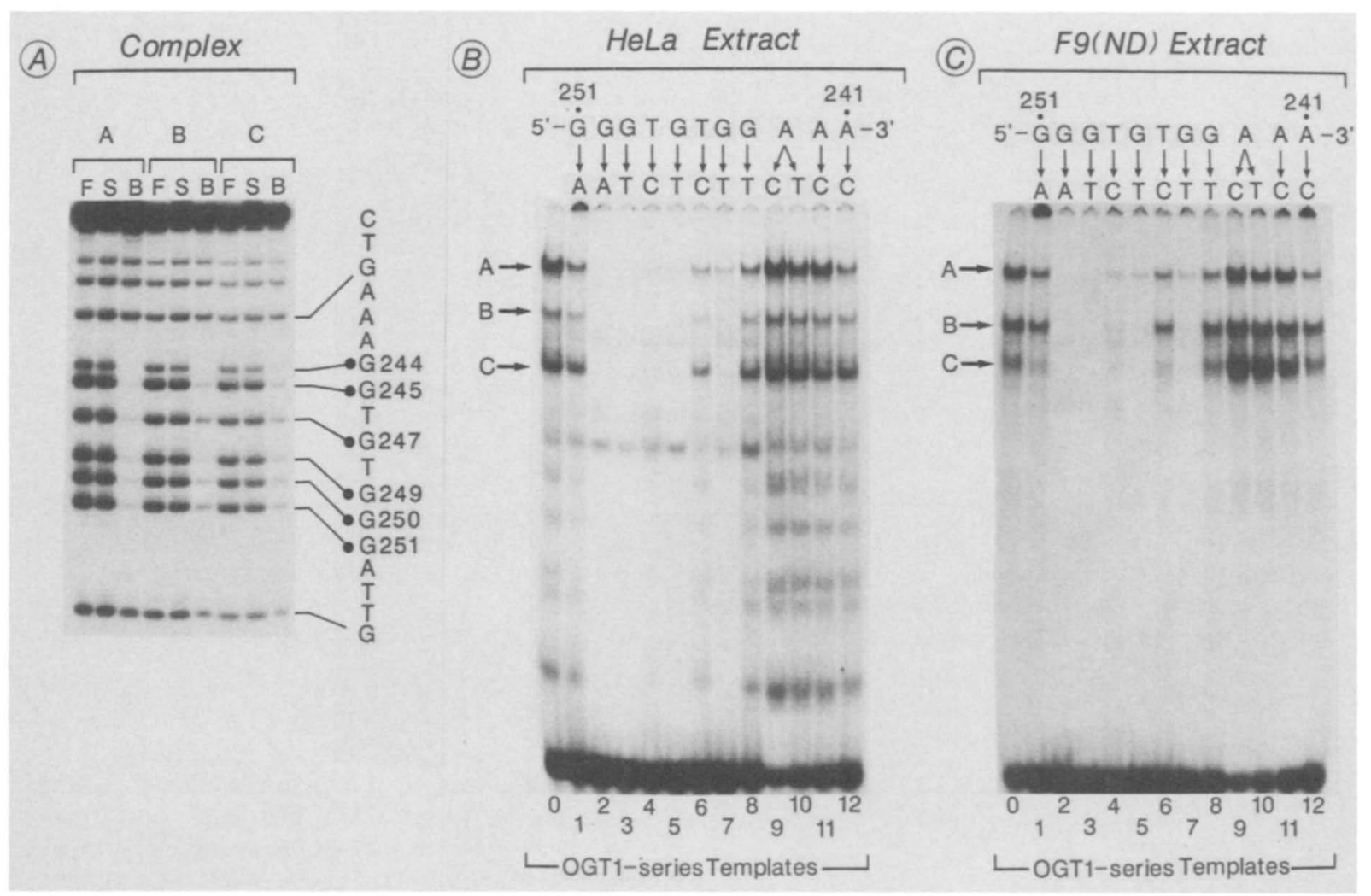

Figure 5. (A) Methylation interference in complexes $A, B$, and $C$ formed with HeLa cell nuclear extracts. pGT1-0 DNA was used as a template. Lanes $F, S$, and $B$ correspond to the unbound DNA, the starting DNA, and the bound DNA from the A, B, or C complexes, respectively. The locations and coordinates of the $G$ residues, the methylation of which interfered with complex formation, are indicated on the right-hand side by a filled circle. The pGT1-0 template was ${ }^{32} \mathrm{P}-5^{\prime}$-end-labeled on the late coding strand, following digestion of the recombinant plasmid with the $K p n I$ isoenzyme Asp-718 which generates a protruding $5^{\prime}$ end. Note that none of the $\mathrm{G}$ residues on the early coding strand of pGT1-0 interfered with complex formation (data not shown). (B) Binding of HeLa cell proteins to the mutated GT-I motif templates. The sequence of the wild-type GT-I motif $(241-251)$ is shown on the top line above the figure and the single point mutations present in each of the respective templates are indicated immediately below. The name of the template in each line is indicated at the bottom of the figure. The locations of the A, B, and C complexes formed using the wild-type GT-I motif in OGT1-0 are indicated on the left-hand side. $(C)$ Binding of $F 9(\mathrm{ND})$ cell proteins to the wild-type and mutated GT-I motif. The nomenclature is the same as in B. The positions of the F9(ND) A, B, and C complexes formed with the wild-type GT-I motif template OGT $1-0$ are indicated to the left of the figure.

GC-rich motifs (I-VI) interacting with the transcription factor Sp1 (Dynan and Tjian 1983; Barrera-Saldana et al. 1985; Gidoni et al. 1985) can prevent the formation of complexes A and B (data not shown). To investigate this finding further, templates containing the wild-type or mutated GC-III motif from the SV40 21-bp repeat region (nucleotides 58-87, see OGC3-0 and OGC3-1 in Fig. 2) were used as competitors.

A comparison of the competition brought about by OGT1-0 (a template containing the wild-type GT-I motif, Fig. 2) and OGC3-0, using pGT1-0 as a template, shows that OGC3-0 competed better than OGT1-0 for the formation of HeLa cell complex A (compare OGT1-0 and OGC3-0 in Fig. 7A). Conversely, the formation of complex $\mathrm{C}$ was competed more efficiently than that of complexes A and B with OGT1-0 as a competitor. No competition was found with the corresponding mutated GT-I and GC-III motifs, OGT1-2 and OGC3-1 (see Figs. 2 and $7 \mathrm{~A}$ ). These results show that protein $\mathrm{C}$ has a much higher affinity for the GT-I motif than for the GC-III motif, and that the converse is true for protein A. Pro- tein B has less affinity for the GT-I motif than protein C (compare the $\mathrm{B} / \mathrm{C}$ ratio in competition with OGT1-0), but has also a lower affinity for the GC-III motif than protein $\mathrm{A}$ (compare the $\mathrm{B} / \mathrm{A}$ ratio in competition with OGC3-0 in Fig. 7A). Similar results were obtained with each of the A, B, and C complexes formed in F9(ND) cell extracts (Fig. 7B), indicating that the F9 protein forming complex $\mathrm{C}$ also has a higher affinity for the GT-I motif than for the GC-III motif.

These results were confirmed using ${ }^{32} \mathrm{P}-5$ '-end-labeled OGC3-0 as a template (Fig. $7 \mathrm{C}$ ). With this template, complexes $\mathrm{A}$ and $\mathrm{B}$, but not $\mathrm{C}$, were formed (complexes $A$ and $B$ were not formed with the mutant OGC3-1, Fig. 7D). Moreover, the A and B complexes were competed more than 10 times better by OGC3-0 than by OGT1-0 (Fig. 7C). Similarly only the A and B complexes were formed with the OGC3-0 template in the F9(ND), CV1, BJA-B, MPC11, Molt-4, and 7OZ/3 (NI) cell extracts (Fig. 7D). In all cases these complexes migrated with the same electrophoretic mobility as those formed using the OGT1-0 template (data not shown). These results show 
that in each of these cell lines the $C$ complexes formed using the GT-I motif template were specific to this motif. The HeLa, BJA-B, and MPC11 proteins forming complexes A and B with either the GC-III or GT-I motifs have identical chromatographic behavior, as the elution profile from the heparin-agarose column was identical using either OGC3-0 or pGT1-0 as templates /data not shown). Taken together with the competition experiments, this result very strongly suggests that the same proteins can form complexes A and B with either motif GT-I or motif $\mathrm{GC}$-III. We conclude that two proteins A and $B$ can interact in vitro with both the GC-III and GT-I motifs, while the protein C is specific to the GT-I motif.

In previous studies (Davidson et al. 1986; Wildeman et al. 1986), it was observed that the GT-I motif of the SV40 enhancer was protected from DNase I digestion by a protein(s) present in nuclear extracts. To determine whether the A, B, or C protein was responsible for this binding activity, we performed competition footprinting experiments using HeLa cell extracts and the labeled SV40 early promoter region from plasmid pA0 as a template for DNase I digestion (Fig. 8A). Competition with 5 pmoles of the wild-type GT-I motif (OGT1-0), but not with the mutated motif (OGT1-2), resulted in a selective deprotection of the GT-I motif /compare the L2 region with each competitor in Fig. 8A) and a disappearance of the L3 hypersensitive site (Fig. 8A; see also Wildeman et al. 1986 and Davidson et al. 1986). With a higher amount (10 pmoles) of OGT1-0, a deprotection of the 21-bp repeat region was also observed, whereas no deprotection was seen with the mutant OGT1-2 (Fig. 8A). These results confirm those of the gel retardation experiments (see above) showing that the proteins interacting with the 21-bp repeat region can also interact with the GT-I motif. In the converse competition footprinting experiment, in which the wild-type GC-III motif of OGC3-0 was used as a competitor, the $21-\mathrm{bp}$ repeat region was selectively deprotected using low concentrations of competitor, while the GT-I motif was not appreciably deprotected, even when using the highest concentration tested [two times more competitor than necessary to completely deprotect the 21-bp repeat region (data not shown)]. Taken together with the results of the gel retardation competition experiments (Fig. 7A,C), which indicate that the protein forming complex $\mathrm{C}$ has a higher affinity for motif GT-I than those forming complexes A and $B$, these competition footprinting experiments strongly suggest that the protection of motif GT-I in the SV40 enhancer was brought about by the protein forming complex $\mathrm{C}$.

To characterize further the binding activity responsible for the DNase I footprint on the GT-I motif of template $\mathrm{pAO}$, the footprints obtained using $\mathrm{HeLa}$ extract and MPC11 extract (which does not form a GT-IC complex, see above) were compared. In each extract, while the 21-bp repeat region was similarly protected, a different pattern of protection was observed over the wildtype enhancer (compare pA0 in each extract in Fig. 8B). Comparison between the footprints brought about by the HeLa and MPC11 cell proteins on the wild-type GT-I

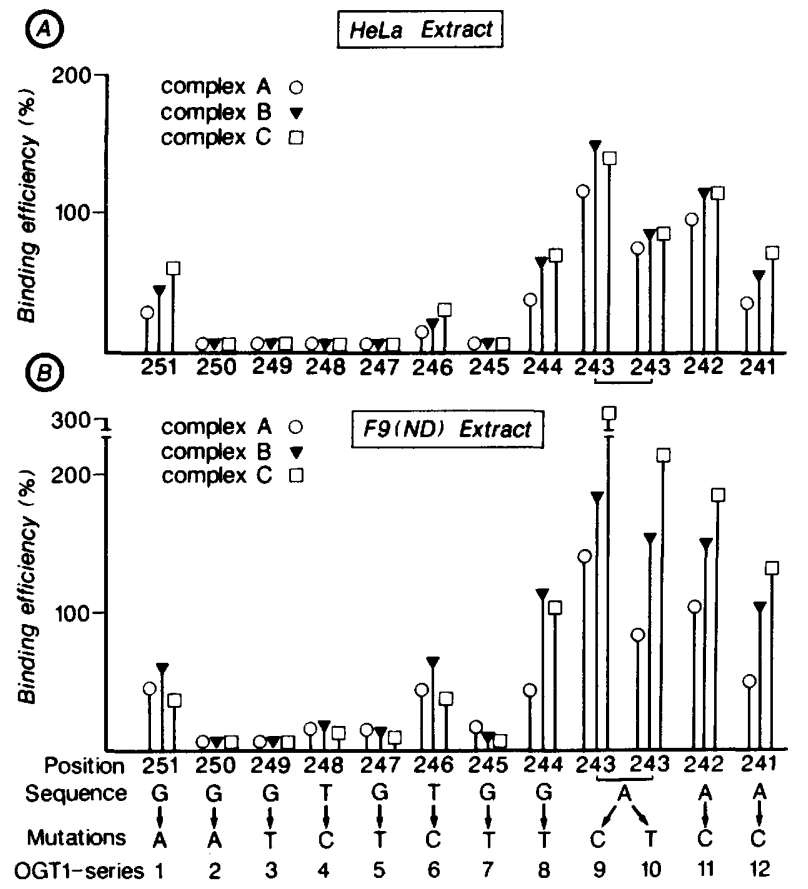

Figure 6. Schematic representation of the effect of single point mutations on the formation of complexes $\mathrm{A}, \mathrm{B}$, and $\mathrm{C}$ with HeLa $(A)$ and F9(ND) $(B)$ nuclear extracts. The quantity of complex formed with each of the mutated templates was determined by densitometric scanning of various exposures of several autoradiograms similar to those shown in Fig. 5, B and C. The same results were obtained in at least two independent experiments. The quantity of complex formed using the wild-type OGT1-0 template is set at $100 \%$, and the value for each mutant shown on the ordinate. The numbers on the abscissa represent the coordinates of the point mutations. The relative values for complexes A $(O), \mathrm{B}(\nabla)$, and $\mathrm{C}(\square)$ are indicated by the open circles, filled triangles, and open squares, respectively. The wild-type GT-I sequence is shown immediately below the abscissa of $B$ and the single point mutations present in the OGT1-series templates below the wild-type sequence.

motif indicates that the prominent HeLa hypersensitive site $\mathrm{L} 3$ and the strong region of protection $\mathrm{L} 2$ are absent in MPC11 extracts. In contrast, the TC-II motif was protected more efficiently in MPC11 than in HeLa cell extracts. Since the sequences recognized by the proteins bound to the GT-I and TC-II motifs may overlap (Macchi et al. 1987), we next used the template pA15 which is specifically mutated in motif TC-II (see Fig. 1). Using HeLa cell extracts and template pA15 resulted in a complete protection of the GT-I motif and an increase in the hypersensitive site $\mathbf{L} 3$, while in MPC11 cell extracts the TC-II motif of pA15 was deprotected and a region of partial protection clearly different from that seen in HeLa extracts was observed within the GT-I motif [compare pAO and pA15 with each extract (Fig. 8B)]. No protection was seen in either extract when both the GT-I and TC-II motifs were simultaneously mutated (see pA1015 in Fig. 8B). Thus, while each extract similarly protects the 21-bp repeat region, a differential pattern of binding to the GT-I motif was observed. Taken together with the gel retardation experiments which indicate that each ex- 


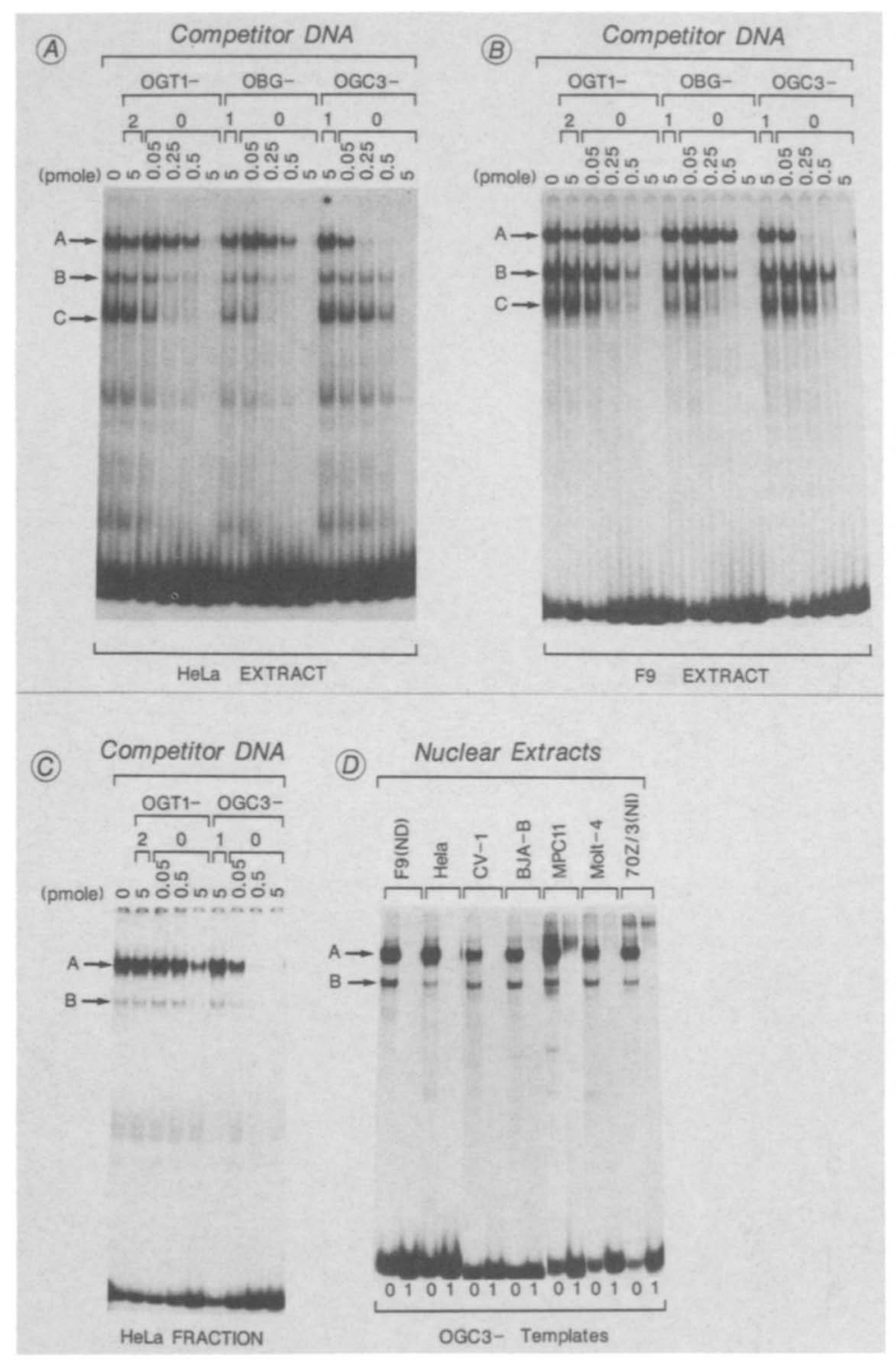

Figure 7. (A) Competition for the formation of HeLa cell complexes A, B, or C by the mouse $\beta$ major-globin promoter upstream element and the GC-rich motif III from the SV40 21-bp repeat region. The positions of the $\mathrm{A}, \mathrm{B}$, and $\mathrm{C}$ complexes formed with the pGT1-0 template present in all lanes are shown on the left. The quantity and nature of the competitor templates are indicated above each lane. Each lane contained $16 \mu \mathrm{g}$ of HeLa cell nuclear extract. OGC3-0 and OGC3-1 contain the wild-type or mutated GC-III motif, whereas OBG-0 and OBG-1 contain the wild-type or mutated upstream element of the mouse $\beta$-major globin promoter from -86 to -95 , see Fig. 2). (B) Same as in $A$, but with the F9(ND) complexes A, B, and C. $(C)$ Complexes A and $B$, but not $C$, are formed with HeLa heparinagarose fractions using the wild-type GC-III motif from the 21-bp repeat region. The quantity and origin of the competitor DNA is indicated above each lane. Binding reactions contained $4 \mu \mathrm{l}$ of HeLa cell protein from chromatography fraction 61 (see Fig. 4A). The positions of the A and B complexes formed with the wild-type GC-III motif in the absence of competitor DNA are indicated on the left of the figure. $(D)$ Complexes $\mathrm{A}$ and $\mathrm{B}$, but not $\mathrm{C}$, are formed in each of the cell lines tested with the wild-type, but not the mutated GC-III motif template. Binding reactions contained $4 \mu \mathrm{g}$ of the nuclear extracts, the origin of which is indicated above each lane, and $2 \mu \mathrm{g}$ of poly $(\mathrm{dA}-\mathrm{dT})$. The positions of the $A$ and $B$ complexes are indicated on the left of the figure. tract forms similar complexes A and B, but that complex $C$ is unique to HeLa cells, these results strongly support the conclusion that the protein-forming complex $\mathrm{C}$ is responsible for the pattern of DNase I protection of the GT-I motif which is observed using HeLa cell extracts and the SV40 early promoter DNA as a template.

Complexes $A, B$, and $C$ are also formed with an upstream element of the $\beta$-globin promoter

A sequence highly homologous to motif GT-I exists in the promoter of the rabbit, human, and mouse $\beta$-globin genes (Dierks et al. 1983; Charnay et al. 1985; Myers et al. 1986; see OBG-0 and OBG-1 in Fig. 2). Genetic analyses have shown that this homologous sequence is essential for the activity of the $\beta$-globin gene promoter in HeLa cells (Dierks et al. 1983; Myers et al. 1986). Using the labeled template OBG-0 containing the wild-type mouse $\beta$-major-globin sequence, complexes $A, B$, and $C$ migrating like their pGT1-0 counterparts were formed (data not shown). Furthermore, the template containing the wild-type $\beta$-globin element, OBG- 0 , but not the corresponding mutated template OBG-1, competed with the pGT1-0 template for the formation of the A, B, and C complexes in both HeLa and F9(ND) cell extracts (Fig. $7 \mathrm{~A}, \mathrm{~B})$. The kinetics of competition for each of the three complexes was very similar to that observed with the homologous GT-I motif, indicating that the protein forming the complex $\mathrm{C}$ with the GT-I motif has a higher affinity for the $\beta$-globin sequence than those forming complexes $\mathrm{A}$ and $\mathrm{B}$.

\section{Discussion}

The protein-binding site of the GT-I motif is not the enhancer core homology

The results presented in this report show that three proteins, designated hereafter proteins GT-IA, GT-IB, and GT-IC, interact with a sequence located in the GT-I region. The "minimal" sequence recognized by the pro- 


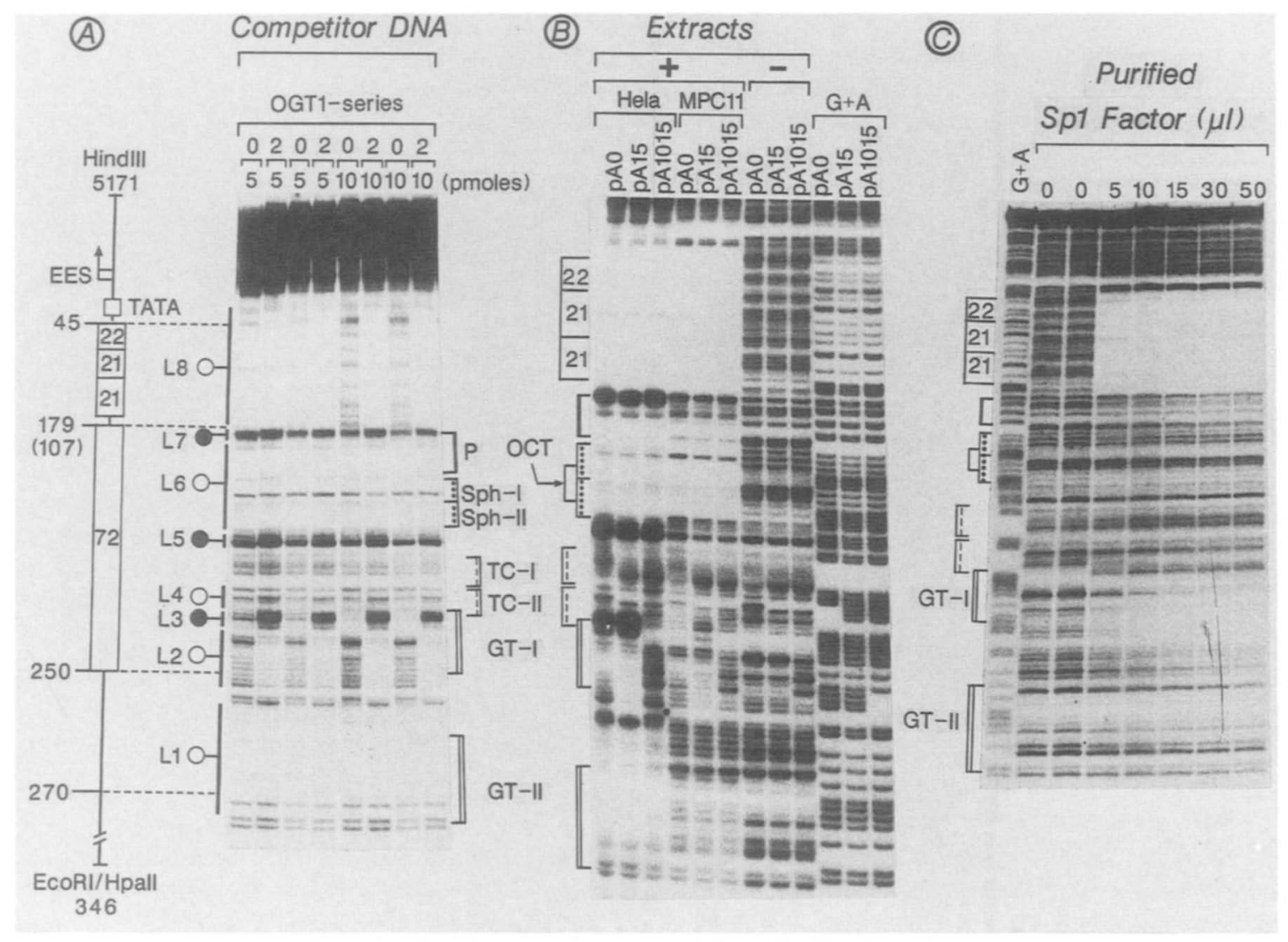

Figure 8. $(A)$ Competition DNase I footprinting experiments with the wild-type and mutated GT-I motifs using the SV40 early promoter from pA0 as a template. The SV40 early promoter was labeled on the late coding strand at the EcoRI site in plasmid pA0/see Wildeman et al. 1986 and Davidson et al. 1986). The positions of the 72-bp element (72), 21-bp repeat region (21, 21, 22), the TATA box, and the early-early mRNA startsites (EES) are shown relative to the DNase I protection pattern, along with the coordinates of the boundaries of the 21 -bp repeat upstream element and of the 72-bp enhancer element. The regions of reduced or enhanced DNase I digestion in the presence of nuclear extract are indicated by the solid bars with open or filled circles, respectively. This pattern is identical to that previously reported (Davidson et al. 1986). The locations of the enhancer sequence motifs are indicated on the right-hand side. The origin and quantity of the competitor DNA are indicated above each lane. All binding reactions contained $6 \mu l$ ( $\sim 80 \mu \mathrm{g}$ protein) of HeLa cell nuclear extract, and $2 \times 10^{4} \mathrm{cpm}(\sim 10 \mathrm{fmoles})^{32} \mathrm{P}-5^{\prime}$-end-labeled DNA. $(B)$ Comparison of the DNase I protection pattern over the GT-I motif in HeLa and MPC11 cell extracts. The SV40 early promoter was labeled as in $A$. The position of the 21 -bp repeat region is indicated by 21,21 , and 22 and the locations of the enhancer motifs are shown to the left of the autoradiogram. OCT indicates the position of the octamer motif, which is specifically protected in the MPC11 extracts (Rosales et al. 1987). The origins of DNA templates and extracts are described in Fig. 1; pA1015 contains the mutations present in both pA10 and pA15. $\mathrm{G}+\mathrm{A}$ shows the sequence of the $\mathrm{G}+\mathrm{A}$ residues of the late strand of each of the templates. Binding reactions contained $2 \times 10^{4} \mathrm{cpm}$ ${ }^{32} \mathrm{P}-5^{\prime}$-end-labeled DNA and $80 \mu \mathrm{g}$ protein $(3-6 \mu \mathrm{l})$ of HeLa or MPC11 nuclear extracts. (-) DNA digested in the absence of added extract. $(C)$ DNase I footprinting experiment using the wild-type SV40 early promoter from pAO as a template and affinity-purified Spl factor. The Spl protein was first separated from the GT-IB and GT-IC proteins by heparin-agarose and DEAE-cellulose chromatography and then affinity-purified according to Kadanoga and Tjian (1986). The SV40 early promoter DNA was ${ }^{32} \mathrm{P}-5^{\prime}$-end-labeled as in $A$. The positions of the 21 -bp repeat region and of the enhancer motifs are indicated on the left of the autoradiogram as in $B$. The first track corresponds to the $\mathrm{G}+\mathrm{A}$ sequence ladder of $\mathrm{pAO}$ as described in $B$. The next two tracks correspond to the profile of digestion of naked DNA by DNase I. The following tracks contain increasing amounts of affinity-purified Spl factor (free of GT-IB and GT-IC proteins) as indicated. Full protection was observed on the 21-bp repeats with $5 \mu l$ of the Spl fraction. An almost complete protection could be seen on the GT-I motif when $30-50 \mu l$ were used.

teins is $5^{\prime}-(251)$ GGGTGTGG-(244)-3', as determined from the analysis of protein binding to mutated templates (Fig. 6) and the competition with a homologous sequence present in an upstream element of the mouse $\beta$-major-globin gene promoter. This recognition sequence overlaps with, but is not identical to, the GT-I motif previously defined on the basis of sequence homology (see Fig. 1 and Zenke et al. 1986).

The GT-I motif exhibits homology with the enhancer core sequence 5'-GTGG A/T A/T A/T G-3' pointed out previously by Laimins et al. (1982) and Weiher et al. (1983). It is noteworthy that the results obtained in vitro with the mutated templates indicate that mutation of the adenine residues of the "core" does not prevent the binding of the protein factors to the GT-I region (Fig. 6). Similarly, mutation of these A residues is not deleterious to the SV40 enhancer activity in vivo in HeLa or F9(ND) cells (see below, and also Zenke et al. 1986 and 
Nomiyama et al. 1987). In contrast, in vitro (Fig. 6) and in vivo (Nomiyama et al. 1987) results indicate that the core motif alone is not sufficient for protein binding and enhancer activity. These results, taken together with the fact that the GT-II motif (Figs. 1 and 2) whose sequence is closely related to the "core" sequence binds a different set of trans-acting factors (see Fig. $3 \mathrm{~B}$ and Xiao et al. 1987 , raise the question as to whether the finding of a core motif has a real predictive value for the presence of a given enhancer element. In this respect, we note also that the Ad2 E1A and the polyoma virus PyEC9.1 enhancer domain $B$, both of which contain a sequence related to the core motif (see legend to Fig. 3), do not compete for the formation of the GT-I complexes.

Recently, Johnson et al. (1987) have characterized a protein EBP20 from rat liver nuclei, which apparently recognizes both the core (GT-I) motif of the SV40 enhancer and the CAAT homology in the herpes simplex virus thymidine kinase gene (HSV-TK). That this protein corresponds to neither the GT-IA, B, nor C proteins described in the present study is indicated by the fact that no competition for formation of complexes $\mathrm{A}, \mathrm{B}$, or $\mathrm{C}$ was observed using the HSV-TK or MHC E $\alpha$ CAAT box motifs.

\section{Relationship between proteins GT-IA and GT-IB and the transcription factor Sp1}

Two of the proteins binding to the GT-I region, GT-IA and GT-IB, were detected in every cell type tested, whereas the GT-IC proteins were cell specific. The results of the gel retardation experiments show that the proteins GT-IA and GT-IB also bind to the GC-III motif of the 21-bp repeat upstream element of the SV40 early promoter. Several lines of evidence suggest that the ubiquitous GT-IA protein forming complex $A$ is in fact the transcription factor $\mathrm{Spl}$, which is known to interact with the GC-rich motif 5'-GGGCGG-3' (Gidoni et al. 1985; Briggs et al. 1987). First, protein GT-IA has the highest affinity for the GC-III motif. Second, no other protein binding to this motif (with the exception of GT-IB, see below/ was detected in any of the chromatography fractions. Third, an activity, which is dependent on the presence of the 21-bp repeat region and which stimulates transcription in vitro from the SV40 early promoter (Vigneron et al. 1984), coeluted with the protein forming complex A (data not shown). This transcriptional activity was already present in the fractions eluted prior to those containing the protein GT-IB /see Fig. 4). That Spl can also bind to the GT-I motif is conclusively demonstrated by the fact that the footprint on the 21-bp repeat region was efficiently competed by the wild type, but not the mutated GT-I motif (Fig. 8A).

The binding of the Spl factor to the enhancer motif GT-I raises the possibility that this protein contributes to enhancer activity. However, this is improbable, as it appears to bind in vitro to the GT-I motif at least 10 times less efficiently than to the GC-III motif /compare the quantity of OGC3-0 and OGT1-0 DNA necessary to compete formation of complex A, using the GC-III or GT-I templates in Fig. 7A,Cl. In addition, the 21-bp re- gion which contains six Spl binding sites (Barrera-Saldana et al. 1985; Gidoni et al. 1985) does not function in vivo as an enhancer element (Benoist and Chambon 1981; Moreau et al. 1981; Barrera-Saldana et al. 1985; Takahashi et al. 1986). Furthermore, although binding of protein GT-IA to the GT-I motif was readily detected in the gel retardation assay, the results of the competition gel retardation and DNase I footprinting experiments indicate that the protein GT-IA (Spl) present in HeLa cell extracts is most likely not responsible for the protection of the GT-I motif within the early promoter of SV40. This conclusion is further supported by the observation that no DNase I footprint equivalent to that observed in HeLa cell extracts could be detected on the GT-I motif using MPC1 1 cell extracts, although the 21-bp repeat region was similarly protected in each case (Fig. 8B). However, specific protection of the GT-I motif against DNase I digestion was observed using the SV40 early promoter template pAO and an amount of affinity-purified Spl protein (Kadonaga and Tjian 1986) free of protein GT-IB and GT-IC at least 10 times higher than that required to protect fully the GC-rich motifs of the 21-bp repeat region (Fig. $8 \mathrm{C}$; note also that none of the other enhancer motifs were protected using the purified factor Sp1). This observation may account for the partial protection (see Fig. 8B) of the GT-I motif of template pA15 using the MPC11 cell extract which does not contain the GT-IC protein. The gel retardation system, therefore, allows the detection of specific, but apparently low-affinity DNA-protein interactions. The use of this system may thus lead to the detection of abundant DNA-binding proteins that have no functional significance in the context of the DNA sequence that is being studied. Whether the binding of a protein to two apparently poorly related sequences reflects the common ancestral origin of groups of promoter elements and of their cognate factors remains to be established.

A second protein GT-IB interacts with both the GT-I and GC-III motifs, but with an affinity different from that of protein GT-IA. In addition, the methylation interference patterns of the GT-IA and GT-IB proteins are not identical (compare A and B in Fig. 5A). These results suggest that protein GT-IB is not a proteolytic product of protein GT-IA. This conclusion is further supported by the observation that, in contrast to protein GT-IA, the GT-IB proteins present in HeLa and F9(ND) cell extracts exhibit different behaviors with the mutated GT-I motif templates (Fig. 6). Thus, although the B complexes of HeLa and F9(ND) cells coelectrophorese, they may not be formed by identical proteins and the GT-IB proteins may therefore exhibit cell specificity. A similar observation was made using the SV40 enhancer domain A, where complexes with identical electrophoretic mobilities were formed by the interaction of two cell-specific proteins with the octamer motif (Rosales et al. 1987). It is unknown whether the GT-IB protein could play a role in the activity of either the SV40 21-bp repeat upstream element or the SV40 enhancer or of the $\beta$-globin promoter. On the other hand, this protein may act as an enhancer factor for another as yet unidentified gene. The situation may then be analogous to that recently found 
for the protein GT-IIB $\alpha$ which interacts with a low affinity with the SV40 GT-II motif, but binds with high affinity to the $\mu \mathrm{E} 3$ motif of the immunoglobulin heavychain gene enhancer (Xiao et al. 1987).

The cell-specific protein GT-IC may be a trans-acting factor both for the SV4O enhancer and the $\beta$-globin promoter

The protein GT-IC exhibits a clear cell specificity. This protein appears to be absent from the MPCll extracts, while the C complexes formed in HeLa, BJA-B, Molt-4, and $\mathrm{F} 9(\mathrm{ND})$ cell extracts all display different electrophoretic mobilities. In addition, the GT-IC proteins present in HeLa and BJA-B cell extracts have different chromatographic properties. The results obtained using the series of mutated GT-I motif templates suggest that the GT-IC proteins present in $\mathrm{HeLa}$ and $\mathrm{F} 9$ (ND) cell extracts recognize sequences that are not identical to those interacting with the GT-IA and GT-IB proteins (see Fig. 6). This suggestion is further supported by the results obtained using the GC-III motif of the 21 -bp repeat region as a template as, in contrast to proteins $A$ and $B$, none of the complexes was formed using this template. Finally, taken altogether, the results of the competition experiments using both the gel retardation and DNase I footprinting assays, and the comparison of the DNase I footprints on motif GT-I in HeLa and MPC11 extracts, suggest very strongly that it is in fact the protein GT-IC which, in HeLa cell nuclear extracts, protects the GT-I motif of the SV40 enhancer from DNase I digestion.

The possible function of the GT-IC proteins can be addressed by a comparison of the in vitro results described here and those obtained in in vivo studies. $\mathrm{Mu}$ tations in the cognate sequence for the GT-I proteins, pA10, pA11, and pA12 (see Fig. 1), all have a marked detrimental effect on the SV40 enhancer activity in vivo in F9(ND) cells (Nomiyama et al. 1987), strongly suggesting that at least one of the F9 cell GT-I proteins acts as a positive trans-acting factor. That the cognate sequence may extend further in the $5^{\prime}$ direction than the sequence defined above is suggested by the fact that the mutations present in pA9 are also detrimental to the in vivo enhancer activity. In contrast, the pA9, pA10, and pA11 mutations have no effect on SV40 enhancer activity in MPC11 cells that do not appear to contain a GT-IC protein, but do contain GT-IA and GT-IB proteins. These observations, taken together with those of the competition gel retardation experiments which show that protein GT-IC has the highest affinity for the GT-I motif, strongly support the idea that the F9 cell protein GT-IC acts as a trans-acting enhancer factor. Moreover, the enhancer activity of mutant pA13 (see Fig. 1) in which all three A residues of the GT-I motif have been mutated to $C$ is markedly increased in F9(ND) cells in vivo (Nomiyama et al. 1987), in agreement with the increased binding of the F9 cell protein GT-IC to similar mutants in vitro (Fig. 6, and data not shown).

Both the fact that the F9 cell protein GT-IC exhibits an apparently different molecular weight and/or charge from its HeLa cell counterpart, and the observation that these two proteins behave differently in response to some of the single point mutations introduced in the GT-I motif (Fig. 6), suggest that the GT-IC proteins may not be identical in the two cell extracts. The role of the HeLa cell protein GT-IC in SV40 enhancer activity in vivo is not immediately obvious. Only one of the recombinants carrying mutations in the sequence important for the binding of this protein in vitro, pA12 (see Fig. 1), has a strong deleterious effect on enhancer activity in vivo (Zenke et al. 1986; Nomiyama et al. 1987). Although the binding of HeLa cell protein GT-IC in vitro shows a clear dependence on the sequences mutated in pA10 and pA11, these mutations have only a small effect in HeLa cells in vivo. This is due to a compensatory effect of motif TC-II which is functional in HeLa, but not in F9(ND) cells, as shown in vivo using recombinants simultaneously mutated in TC-II and GT-I motifs (Nomiyama et al. 1987; e.g., mutant 1015, see Fig. 8B). That the HeLa cell protein GT-IC has an activity in vivo is suggested by the observation that, like the F9 cell protein GT-IC, it binds with a higher affinity than the GT-IA and GT-IB proteins to the homologous sequence present in the $\beta$-globin promoter. Introduction of single point mutations (indicated by the stars in Fig. 2) in this $\beta$-globin upstream element has a deleterious effect on the promoter activity in vivo in HeLa cells (Myers et al. 1986). The introduction of equivalent mutations in the SV40 GT-I motif inhibits the binding of HeLa cell protein GT-IC (Fig. 6). It has also been observed that this homologous $\beta$-globin sequence is protected from DNase I digestion by protein(s) present in HeLa cell extracts (Jones et al. 1987). Our gel retardation competition experiments suggest strongly that this protein is in fact the GT-IC protein present in both HeLa and F9(ND) cells.

It appears therefore that the protein GT-IC may be a trans-acting factor for both an enhancer motif and a promoter upstream element, a situation similar to that previously encountered for factors that bind to the octamer motif present in both enhancer and promoter upstream elements (Singh et al. 1986; Sive and Roeder 1986; Bohmann et al. 1987). At present the roles of the BJA-B and Molt-4 GT-IC proteins are unknown; although they both exhibit a higher affinity for the enhancer GT-I motif than for the GC-rich motifs of the 21-bp repeat region, they appear to be physically different from both their HeLa and F9 cell counterparts. Studies of the activity of multimers of the GT-I motif in various cell types in vivo and purification of the different proteins binding to this motif are clearly required to elucidate their role in the mechanism of enhancer and promoter activity.

\section{Materials and methods}

Preparation of nuclear extracts and chromatography

Nuclear extracts were prepared according to the method of Dignam et al. (1983) with the modifications described by Xiao et al. (1987). Extracts from F9(ND), CV1, 7OZ/3(NI), and MPC11 cells were prepared in the presence of the protease inhibitors aprotinin $(5 \mu \mathrm{g} / \mathrm{ml})$, leupeptin $(30 \mu \mathrm{g} / \mathrm{ml})$, pepstatin (5 $\mu \mathrm{g} / \mathrm{ml}$ ), and $0.2 \mathrm{mM}$ phenylmethylsulfonyl fluoride (PMSF). Protein concentration was measured by the method of Bradford 
(1976). All extracts were dialysed against buffer A containing 20 mM HEPES (pH 7.9), $1 \mathrm{~mm} \mathrm{MgCl}, 1 \mathrm{~mm}$ DTT, $20 \mathrm{~mm} \mathrm{KCl}, 0.5$ $\mathrm{mM}$ PMSF, and $25 \%$ (wt/vol) glycerol. Heparin-agarose chromatography was performed as described elsewhere (Xiao et al. 1987). Briefly, $5 \mathrm{ml}$ of extract $(4 \mathrm{mg} / \mathrm{ml})$ in buffer $A$ was applied to a $20-\mathrm{ml}$ heparin-agarose column and the column was washed with 3 volumes of buffer A containing $0.1 \mathrm{M} \mathrm{KCl}$. The retained proteins were eluted with a $60-\mathrm{ml}$ linear $0.2-0.6 \mathrm{M} \mathrm{KCl}$ gradient. One-milliliter fractions were collected and the $\mathrm{KCl}$ concentration determined by conductivity. The fractions were then dialyzed against buffer A, frozen in liquid nitrogen, and stored at $-70^{\circ} \mathrm{C}$. The proteins were purified three- to fivefold by this chromatography step.

\section{Construction of recombinant plasmids and preparation of DNA templates}

The pGT1-0, pGT1-1, pGT2-0, and pGT2-1 templates (Fig. 2) were cloned between the $K p n I$ and $B a m H I$ sites in a modified pUC18 vector (Rosales et al. 1987) by shotgun ligation of synthetic complementary oligonucleotides /Grundström et al. 1985). The nucleotide sequence of the inserts was determined (Sanger et al. 1977) and the plasmid DNA prepared by standard methods (Zenke et al. 1986). The ${ }^{32}$ P-5'-end-labeled DNA templates prepared from the recombinant plasmids, the unlabeled competitors, and the labeled oligonucleotide templates were obtained as described elsewhere (Rosales et al. 1987; Xiao et al. 1987).

\section{Gel retardation and DMS methylation interference assays}

Gel retardation assays were performed essentially as described by Strauss and Varshavsky (1984) with the modifications of Singh et al. (1986). DNA-protein complexes were formed in the presence of $2 \mu \mathrm{g}$ of either poly(dA-dT) or poly(dI-dC) as described (Xiao et al. 1987) and resolved on $7 \%$ polyacrylamide gels $(30: 1$ cross-linking ratio) containing $6.7 \mathrm{mM}$ Tris- $\mathrm{HCl}(\mathrm{pH}$ $7.51,3.3 \mathrm{~mm}$ sodium acetate, and $1 \mathrm{mM}$ EDTA. Electrophoresis was performed at $25 \mathrm{~mA}$ until a suitable separation had been achieved, after which the gel was dried and subjected to autoradiography.

Methylation interference assays were carried out by the method of Hendrickson and Schleif (1985). ${ }^{32}$ P-5'-End-labeled DNA $\left(2 \times 10^{6} \mathrm{cpm}\right)$ fragments were partially methylated at the guanine $(G)$ residues by treatment with dimethylsulfate (DMS) (Rosales et al. 1987). The methylated DNA was ethanol-precipitated, washed with $70 \%$ ethanol, and $2 \times 10^{5} \mathrm{cpm}$ used as template in gel retardation assays as described above. After electrophoresis the wet gel was autoradiographed at $4^{\circ} \mathrm{C}$ overnight, and the complexed and free DNA excised from the gel and recovered by electroelution. The DNA samples were then cleaved by treatment with piperidine (Maxam and Gilbert 1980) and the reaction products analyzed on a $15 \%$ polyacrylamide-urea gel.

\section{Gel retardation competition assays}

The unlabeled competitor DNA was mixed with the labeled template before addition to the binding reaction. Binding reactions and gel electrophoresis were carried out as described (see above, and Xiao et al. 1987).

\section{DNase I footprinting assays}

The preparation of the ${ }^{32} \mathrm{P}-5$ '-end-labeled SV40 early promotercontaining fragment from plasmid $\mathrm{pAO}$ and the DNase I footprinting assay was performed as previously described (Davidson et al. 1986; Wildeman et al. 1986). The pA0-derived template and double-stranded competitor oligonucleotides were pre- mixed before addition to the reactions, each of which contained $6 \mu \mathrm{l}$ of HeLa cell nuclear extract and 5-10 fmoles $\left(1-2 \times 10^{4}\right.$ cpm) of ${ }^{32} \mathrm{P}-5^{\prime}$-end-labeled DNA template.

\section{Acknowledgments}

We would like to extend our gratitude to F. Ruffenach for assistance in the preparation of the oligonucleotides. We also thank C. Werlé and B. Boulay for the illustrations, the secretarial staff for typing the manuscript, and M. Acker for technical assistance with the cell culture. The MHC E $\alpha$ oligonucleotides were a generous gift of Drs. A. Dorn and D. Mathis. I.D., M.M., R.R., and J.-H.X. were supported by fellowships from the Royal Society of Great Britain, The American Cancer Society (PF2640), the Universite Louis Pasteur and the French Government, respectively. This work was supported by grants from the CNRS (ATP 6984), the INSERM, the Foundation pour la Recherche Médicale, the Ministère de la Recherche et de la Technologie (84V0803), and the Association pour le Développement de la Recherche sur le Cancer.

\section{References}

Augereau, P. and P. Chambon. 1986. The mouse immunoglobulin heavy-chain enhancer: Effect on transcription in vitro and binding of proteins present in HeLa and lymphoid B cell extracts. EMBO I. 5: 1791-1797.

Banerii, J., S. Rusconi, and W. Schaffner. 1981. Expression of a $\beta$-globin gene is enhanced by remote SV40 DNA sequences. Cell 27: 299-308.

Banerii, J., L. Olson, and W. Schaffner. 1983. A lymphocyte-specific cellular enhancer is located downstream of the joining region in immunoglobulin heavy chain genes. Cell 33: 729740.

Barrera-Saldana, H., K. Takahashi, M. Vigneron, A. Wildeman, I. Davidson, and P. Chambon. 1985. All six GC-motifs of the SV40 early upstream element contribute to promoter activity in vivo and in vitro. EMBO J. 4: 3839-3849.

Barrett, P., L. Clark, and R.T. Hay. 1987. A cellular protein binds to a conserved sequence in the adenovirus type 2 enhancer. Nucleic Acids Res. 15: 2719-2735.

Benoist, C. and P. Chambon. 1981. The SV40 early promoter region: Sequence requirements in vivo. Nature 290: 304310.

Bohmann, D., W. Keller, T. Dale, H.R. Schöler, G. Tebb, and I.W. Mattaj. 1987. A transcription factor which binds to the enhancers of SV40, immunoglobulin heavy chain and U2 snRNA genes. Nature 325: 268-272.

Borrelli, E., R. Hen, and P. Chambon. 1984. Adenovirus-2 E1A products repress enhancer-induced stimulation of transcription. Nature 312: 608-612.

Bradford, M.M. 1976. A rapid and sensitive method for the quantitation of microgram quantities of protein utilizing the principle of protein-dye binding. Anal. Biochem. 72: 248254.

Briggs, M.R., J.T. Kadonaga, S.P. Bell, and R. Tjian. 1986. Purification and biochemical characterization of the promoterspecific transcription factor, Spl. Science 234: 47-52.

Chambon, P., A. Dierich, M.P. Gaub, S. Jakowlev, J. Jongstra, A. Krust, J.P. LePennec, P. Oudet, and T. Reudelhuber. 1984. Promoter elements of genes coding for proteins and modulation of transcription by oestrogens and progesterone. Rec. Progr. Horm. Res. 40: 1-42.

Charnay, P., P. Mellon, and T. Maniatis. 1985. Linker scanning mutagenesis of the 5 '-flanking region of the mouse $\beta$-majorglobin gene: Sequence requirements for transcription in ery- 
throid and nonerythroid cells. Mol. Cell. Biol. 5: 14981151.

Davidson, I., C. Fromental, P. Augereau, A. Wildeman, M. Zenke, and P. Chambon. 1986. Cell-type specific protein binding to the enhancer of simian virus 40 in nuclear extracts. Nature 323: 544-548.

Dierks, P., A. Van Ooyen, M.D. Cochran, C.S. Dobkin, J. Reiser, and C. Weissmann. 1983. Three regions upstream from the cap site are required for efficient and accurate transcription of the rabbit $\beta$-globin gene in mouse $3 \mathrm{~T} 6$ cells. Cell 32: 695-706.

Dignam, J.D., R.M. Lebovitz, and R.G. Roeder. 1983. Accurate transcription initiation by RNA polymerase II in a soluble extract from isolated mammalian nuclei. Nucleic Acids Res. 11: 1475-1489.

Dougherty, J.P., P. Augereau, and P. Chambon. 1986. The mouse immunoglobulin heavy-chain gene enhancer contains sequences that inhibit transcription in vitro in Hela cell extracts. Mol. Cell. Biol. 6: 4117-4121.

Dynan, W.S. and R. Tjian. 1983. Isolation of transcription factors that discriminate between different promoters recognized by RNA polymerase II. Cell 32: 669-680.

Ephrussi, A., G.M. Church, S. Tonegawa, and W. Gilbert. 1985. B lineage-specific interactions of an immunoglobulin enhancer with cellular factors in vivo. Science 227: 134-138.

Fried, M. and D.M. Crothers. 1981. Equilibria and kinetics of lac repressor-operator interactions by polyacrylamide gel electrophoresis. Nucleic Acids Res. 9: 6505-6525.

Gamer, M.M. and A. Revzin. 1981. A gel electrophoresis method for quantifying the binding of proteins to specific DNA regions: Application to components of the Escherichia coli lactose operon regulatory system. Nucleic Acids Res. 9: 3047-3060.

Gidoni, D., J.T. Kadonaga, H. Barrera-Saldana, K. Takahashi, P. Chambon, and R. Tjian. 1985. Bidirectional SV40 transcription mediated by tandem $\mathrm{Spl}$ binding interactions. Science 230: $511-517$.

Gillies, S.D., S.L. Morrison, V.T. Oi, and S. Tonegawa. 1983. A tissue-specific transcription enhancer element is located in the major intron of a rearranged immunoglobulin heavy chain gene. Cell 33: 717-728.

Grundström, T., W.M. Zenke, M. Wintzerith, H.W.D. Matthes, A. Staub, and P. Chambon. 1985. Oligonucleotide-directed mutagenesis by microscale "shot-gun" gene synthesis. $\mathrm{Nu}$ cleic Acids Res. 13: 3305-3316.

Hen, R., E. Borrelli, P. Sassone-Corsi, and P. Chambon. 1983. An enhancer element is located 340 base pairs upstream from the adenovirus-2 E1A capsite. Nucleic Acids Res. 11: $8747-8760$.

Hendrickson, W. and R. Schleif. 1985. A dimer of AraC protein contacts three adjacent major groove regions of the araI DNA site. Proc. Natl. Acad. Sci. 82: 3129-3133.

Herbomel, P., B. Bourachot, and M. Yaniv. 1984. Two distinct enhancers with different cell specificities coexist in the regulatory region of polyoma. Cell 39: 653-662.

Herr, W. and J. Clarke. 1986. The SV40 enhancer is composed of multiple functional elements that can compensate for one another. Cell 45: 461-470.

Johnson, P.F., W.H. Landschulz, B.J. Graves, and S.L. McKnight. 1987. Identification of a rat liver nuclear protein that binds to the enhancer core element of three animal viruses. Genes Dev. 1: 133-146.

Jones, K.A., J.T. Kadonaga, P.J. Rosenfeld, T.J. Kelly, and R. Tjian. 1987. A cellular DNA-binding protein that activates eukaryotic transcription and DNA replication. Cell 48: 7989.

Kadonaga, J.T. and R. Tjian. 1986. Affinity purification of se- quence-specific DNA binding proteins. Proc. Natl. Acad. Sci. 83: 5889-5893.

Klein, G., B. Giovanella, A. Westman, J.S. Stehlin, and D. Munford. 1975. An EBV-genome-negative cell line established from an American Burkitt lymphoma; receptor characteristics. EBV infectibility and permanent conversion into EBV-positive-sublines by in vitro infection. Intervirology 5: 319-334.

Laimins, L.A., G. Khoury, C. Gorman, B. Howard, and P. Gruss. 1982. Host-specific activation of transcription by tandem repeats from simian virus 40 and Moloney murine sarcoma virus. Proc. Natl. Acad. Sci. 79: 6453-6457.

Maxam, A. and W. Gilbert. 1980. Sequencing end-labeled DNA with base-specific chemical cleavages. Methods Enzymol. 65: 499-525.

McKnight, S.L., R.C. Kingsbury, A. Spence, and M. Smith. 1984. The distal transcriptional signals of the herpesvirus TK gene share a common hexanucleotide control sequence. Cell 37: 253-262.

Mercola, M., J. Goverman, C. Mirell, and K. Calame. 1985. Immunoglobulin heavy-chain enhancer requires one or more tissue-specific factors. Science 227: 266-270.

Minowada, J., T. Ohnuma, and G.E. Moore. 1972. Rosetteforming human lymphoid cell lines. I. Establishment and evidence for origin of thymus-derived lymphocytes. J. Natl. Cancer Inst. 49: 891-895.

Moreau, P., R. Hen, B. Wasylyk, R. Everett, M.P. Gaub, and P. Chambon. 1981. The SV40 72 base repair repeat has a striking effect on gene expression both in SV40 and other chimeric recombinants. Nucleic Acids Res. 9: 6047-6068.

Myers, R.M., K. Tilly, and T. Maniatis. 1986. Fine structure genetic analysis of a $\beta$-globin promoter. Science 232: 613-618.

Nomiyama, H., C. Fromental, and P. Chambon. 1987. Cell-specific activity of the various elements of the SV40 enhancer. Proc. Natl. Acad. Sci. (in press).

Paige, C.J., P.W. Kincade, and P. Ralph. 1978. Murine B cell leukemia line with inducible surface immunoglobulin expression. I. Immunol. 121: 641-647.

Peterson, C.L., K. Orth, and K.L. Calame. 1986. Binding in vitro of multiple cellular proteins to immunoglobulin heavychain enhancer DNA. Mol. Cell. Biol. 6: 4168-4178.

Picard, D. 1985. Viral and cellular transcription enhancer. In Oxford surveys on eukaryotic genes, vol. 2, pp. 24-48. Oxford University Press, Oxford.

Pruijn, G.J.M., W. van Driel, and P.C. van der Vliet. 1986. Nuclear factor III, a novel sequence-specific DNA-binding protein from HeLa cells stimulating adenovirus DNA replication. Nature 322: 656-659.

Queen, C. and D. Baltimore. 1983. Immunoglobulin gene transcription is activated by downstream sequence elements. Cell 33: $741-748$.

Rosales, R., M. Vigneron, M. Macchi, I. Davidson, J.H. Xiao, and P. Chambon. 1987. In vitro binding of cell-specific and ubiquitous nuclear proteins to the octamer motif of the SV40 enhancer and related motifs present in other promoters and enhancers. $E M B O /$. (in press).

Rosenfeld, P.J. and T.J. Kelly. 1986. Purification of nuclear factor I by DNA recognition site affinity chromatography. J. Biol. Chem. 261: 1398-1408.

Rosenfeld, P.J., E.A. O'Neill, R.J. Wides, and T.J. Kelly. 1987. Sequence-specific interactions between cellular DNAbinding proteins and the adenovirus origin of DNA replication. Mol. Cell. Biol. 7: 875-886.

Sakaguchi, N., T. Kishimoto, H. Kikutami, T. Watanabe, N. Yoshida, A. Shimizu, Y. Yamawaki-Kataoda, T. Honjo, and Y. Yamamura. 1980. Induction and regulation of immuno- 
globulin expression in a murine pre-B cell line 7OZ/3. J. Immunol. 125: 2654-2659.

Sanger, F., S. Nicklen, and A.R. Coulson. 1977. DNA sequencing with chain-terminating inhibitors. Proc. Natl. Acad. Sci. 74: 5463-5467.

Sassone-Corsi, P. and E. Borrelli. 1986. Transcriptional regulation by trans-acting factors. Trends Genet. 2: 215-219.

Sassone-Corsi, P., J.P. Dougherty, B. Wasylyk, and P. Chambon. 1984. Stimulation of in vitro transcription from heterologous promoters by the simian virus 40 enhancer. Proc. Natl. Acad. Sci. 81: 308-312.

Sassone-Corsi, P., A. Wildeman, and P. Chambon. 1985. A trans-acting factor is responsible for the simian virus 40 enhancer activity in vitro. Nature 313: 458-463.

Schirm, S., J. Jiricny, and W. Schaffner. 1987. The SV40 enhancer can be dissected into multiple segments, each with a different cell type specificity. Genes Dev. 1: 65-74.

Schöler, H.R. and P. Gruss. 1984. Specific interaction between enhancer-containing molecules and cellular components. Cell 36: 403-411.

1985. Cell type-specific transcriptional enhancement in vitro requires the presence of trans-acting factors. $E M B O J$. 4: 3005-3013.

Schöler, H., A. Haslinger, A. Heguy, H. Holtgreve, and M. Karin. 1986. In vivo competition between a metallothionein regulatory element and the SV40 enhancer. Science 232: 76-80.

Sen, R. and D. Baltimore. 1986. Multiple nuclear factors interact with the immunoglobulin enhancer sequences. Cell 46: 705-716.

Serfling, E., M. Jasin, and W. Schaffner. 1985. Enhancers and eukaryotic gene transcription. Trends Genet. 1: 224-230.

Sergeant, A., D. Bohmann, H. Zentgraf, H. Weiher, and W. Keller. 1984. A transcription enhancer acts in vitro over distances of hundreds of base-pairs on both circular and linear templates but not on chromatin-reconstituted DNA. J. Mol. Biol. 180: 577-600.

Singh, H., R. Sen, D. Baltimore, and P.A. Sharp. 1986. A nuclear factor that binds to a conserved sequence motif in transcriptional control elements of immunoglobulin genes. Nature 319: 154-158.

Sive, H.L. and R.G. Roeder. 1986. Interaction of a common factor with conserved promoter and enhancer sequences in histone H2B, immunoglobulin, and U2 small nuclear RNA (snRNA) genes. Proc. Natl. Acad. Sci. 83: 6382-6386.

Strauss, F. and A. Varshavsky. 1984. A protein binds to a satellite DNA repeat at three specific sites that would be brought into mutual proximity by DNA folding in the nucleosome. Cell 37: 889-901.

Takahashi, K., M. Vigneron, H. Matthes, A. Wildeman, M. Zenke, and P. Chambon. 1986. Requirement of stereospecific alignments for initiation from the simian virus 40 early promoter. Nature 319: 121-126.

Tooze, J. 1982. Molecular biology of tumor viruses, 2nd ed., part 2, revised. DNA tumor viruses. Cold Spring Harbor Laboratory, Cold Spring Harbor, New York.

Vigneron, M., H.A. Barrera-Saldana, D. Baty, R.E. Everett, and P. Chambon. 1984. Effect of the 21-bp repeat upstream element on in vitro transcription from the early and late SV40 promoters. $E M B O$ J. 3: 2373-2382.

Walker, M.D., T. Edlund, A.M. Boulet, and W.J. Rutter. 1983. Cell-specific expression controlled by the $5^{\prime}$-flanking region of insulin and chymotrypsin genes. Nature 306: 557-561.

Wasylyk, B. 1986. Protein coding genes of higher eukaryotes: Promoter elements and trans-acting factors. In Maximizing gene expression (ed. W. Reznikoff and L. Gold), pp. 79-99. Butterworths, Boston.
Wasylyk, C., J.L. Imler, J. Perez-Mutul, and B. Wasylyk. 1987. The c-Ha-ras oncogene and a tumor promoter activate the polyoma virus enhancer. Cell 48: $525-534$.

Weiher, H., M. König, and P. Gruss. 1983. Multiple point mutations affecting the simian virus 40 enhancer. Science 219: 626-631.

Weinberger, J., D. Baltimore, and P.A. Sharp. 1986. Distinct factors bind to apparently homologous sequences in the immunoglobulin heavy-chain enhancer. Nature 322: 846-848.

Wildeman, A., P. Sassone-Corsi, T. Grundström, M. Zenke, and P. Chambon. 1984. Stimulation of in vitro transcription from the SV40 early promoter by the enhancer involves a specific trans-acting factor. $E M B O I .3: 3129-3133$.

Wildeman, A., M. Zenke, C. Schatz, M. Wintzerith, T. Grundström, H. Matthes, K. Takahashi, and P. Chambon. 1986. Specific protein binding to the simian virus 40 enhancer in vitro. Mol. Cell. Biol. 6: 2098-2105.

Xiao, J.H., I. Davidson, R. Rosales, D. Ferrandon, M. Vigneron, M. Macchi, F. Ruffenach, and P. Chambon. 1987. One cellspecific and three ubiquitous nuclear proteins bind in vitro to overlapping motifs in the domain Bl of the SV40 enhancer. $E M B O J$. (in press).

Zenke, M., T. Grundström, H. Matthes, M. Wintzerith, C. Schatz, A. Wildeman, and P. Chambon. 1986. Multiple sequence motifs are involved in SV40 enhancer function. $E M B O$ I. 5: $387-397$. 


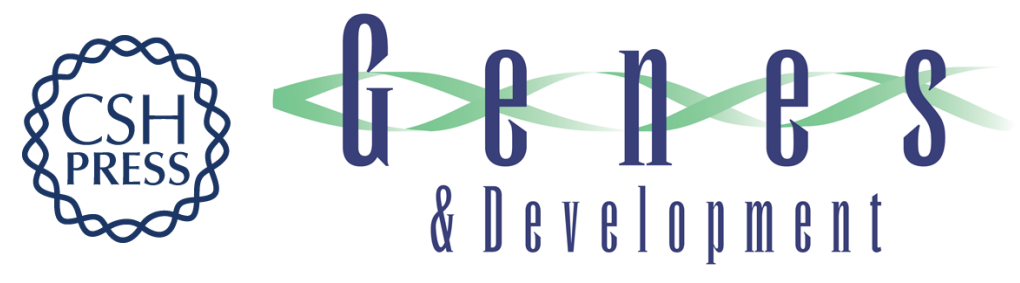

\section{In vitro binding of several cell-specific and ubiquitous nuclear proteins to the GT-I motif of the SV40 enhancer.}

J H Xiao, I Davidson, M Macchi, et al.

Genes Dev. 1987, 1:

Access the most recent version at doi:10.1101/gad.1.8.794

References This article cites 68 articles, 23 of which can be accessed free at: http://genesdev.cshlp.org/content/1/8/794.full.html\#ref-list-1

License

Email Alerting

Receive free email alerts when new articles cite this article - sign up in the box at the top Service right corner of the article or click here.

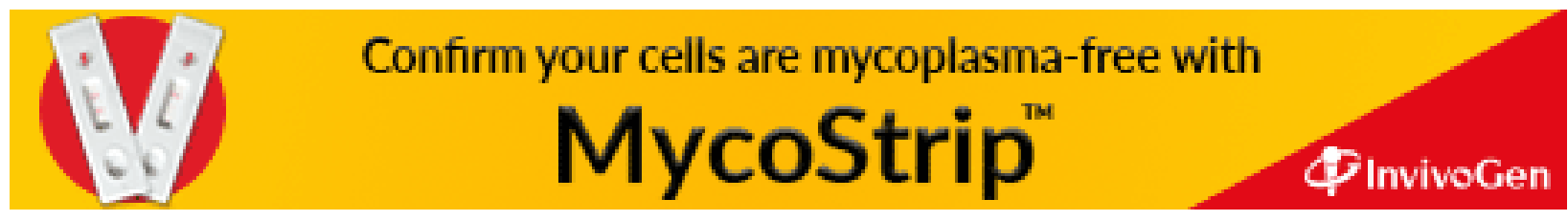

